\title{
Reverse PDA - Less Common Type Of Patent Ductus Arteriosus - Case Report
}

\author{
Iuliu SCURTU ${ }^{1 *}$, Cosmin PESTEAN ${ }^{2}$, Radu LACATUS ${ }^{3}$, Meda LASCU ${ }^{4}$, Mircea MIRCEAN ${ }^{1}$, Razvan CODEA ${ }^{1}$, \\ Cristian POPOVICI ${ }^{1}$, Robert PURDOIU ${ }^{3}$, Gavril GIURGIU ${ }^{1}$ \\ ${ }^{1}$ Department of Internal Medicine. USAMV Cluj-Napoca, Romania \\ ${ }^{2}$ Department of Anaesthesiology. USAMV Cluj-Napoca, Romania \\ ${ }^{3}$ Department of Radiology, USAMV Cluj-Napoca, Romania \\ ${ }^{4}$ Happy Pets Clinic, Oradea, Romania \\ *corresponding author: iuliu.scurtu@usamvcluj.ro
}

\begin{abstract}
PDA represents one of the most frequently diagnosed type of congenital heart disease. Ductus arteriosus is a normal structure in foetal life, which permits shunting of oxygenated blood from the pulmonary artery into the aorta. Failure of sealing after birth is an abnormal condition and is called patent ductus arteriosus. In normal PDA, due to fact that systemic pressure is fivefold higher than pulmonary circulation, blood is shunted from the aorta into the pulmonary artery. In reverse PDA, pulmonary artery pressure does not drop after birth, and blood will be shunted form right to left. in our study we want to evaluate clinical, haematological, ECG and echocardiographic changes in case of reverse PDA.

Two-year old female Bichon Frise was referred to our clinic with signs of effort intolerance and dyspnoea for more than a year. ECG was performed in the right lateral recumbency using a digital device and echocardiography was done with Esaote MyLab40 Vet with a phased array transducer matched with the size of the dog (7.5 MHz). Haematology and blood biochemistry were also done.

We identified a dog with a good body score, quite alert and without any sign of illness. Haematological investigation underlined polycythaemia and very high PCV. The ECG revealed a normal sinus rhythm with a deep $S$ wave, changes consistent with right ventricle enlargement. Right atrial dilation and right ventricle hypertrophy were found on cardiac ultrasonography. The right ventricle free wall was hypertrophied and interventricular septum was flattened, changes consistent with increased pressure on the right side of the heart. The left heart was small. Positive diagnosis was done, performing "bubble study" and identification of contrast bubble within the abdominal aorta.

Reverse PDA is a rarely diagnosed congenital heart disease. Polycythaemia in young dogs could raise the suspicion of reverse PDA. For positive diagnosis, echocardiography and bubble study are required. ECG is not a sensitive tool for diagnosis.
\end{abstract}

Keywords: bubble study, congenital heart disease, echocardiography, reverse PDA

\section{INTRODUCTION}

Patent ductus arteriosus (PDA) is the second (Oliveira et al., 2011) or the third (Scrope, 2015) most frequently diagnosed congenital heart pathology. Ductus arteriosus in foetal life permits shunting of the oxygenated blood from the pulmonary artery into the aorta, this way bypassing non-functional lungs (Israel et al., 2003).
After birth, ductus arteriosus closure occurs in two phases: (1) smooth muscle contraction within 1824 hours after birth; (2) anatomic occlusion of the lumen over the next few days or weeks (Gournay, 2011). An increase in arterial p02, a decrease in circulating $\mathrm{PgE}_{2}$ and a drop in pulmonary blood pressure contribute to closure of ductus (Gournay, 2011). In classic PDA blood flows from left-to-right 
(systemic pressure usually is fivefold higher than pulmonary circulation), but in some instances, blood shunts from right-to-left due to increased pulmonary vasculature resistance (Seibert et al., 2011). This may occur due to persistence of foetal pulmonary physiology (pulmonary hypertension) or in case of large diameter shunts (Seibert et al., 2011).

\section{MATERIAL AND METHODS}

A two-year old Bichon Frise, intact female, 2.3 $\mathrm{kg}$ was referred to the Cardiology department of the Faculty of Veterinary Medicine, of Cluj-Napoca, for cardiac examination due to fainting episodes and effort intolerance.

Heamatological investigations were done using Abacus Vet 5-diff device. For biochemical analyses, we used Arkray Spotchem 4430 device. Parameters investigated were aspartate transaminase (ASAT), alanine transaminase (ALAT), blood urea nitrogen (BUN), creatinine (creat), cholesterol (chol), triglycerides (TG), calcium, total protein (TP) and magnesium (Mg).

ECG was recorded with a digital device (Poly Spectrum) using 6 standard leads. To perform the ECG, the dog was restrained in the right lateral recumbency, with front legs being placed perpendicular to the body, and hind legs being placed semi-flexed.

Echocardiography was done with an Esaote MyLab 40 Vet ultrasound equipped with a 7.5 $\mathrm{MHz}$ phased array probe and it was performed by an experienced investigator. The hair was clipped in the right and left thorax region, and echocardiography was performed using a cut-out table from underneath.

We subjectively evaluated the chambers' sizes and dimensions from the long axis view (Lax). We evaluated the left ventricle chamber's diameters at the level of papillary muscle in M-mode from the short axis view (Sax). At the base of the heart, we assessed the aorta to left atrium ratio, pulmonary artery diameter, pulmonary flow (velocity and symmetry), and the presence of pulmonary valve insufficiency. Mitral and tricuspid inflow were assessed from left apical four chambered view. Five chambered apical view was used to characterise aortic velocity and the presence of aortic valve insufficiency.

The bubble study was performed by the administration of $6 \mathrm{ml}$ agitated saline solution into a cephalic vein followed by identification of microbubbles into the abdominal aorta.

\section{RESULTS AND DISCUSSION}

The owner started to notice clinical sign abnormalities at the dog when it was 10 months old. Initially, effort intolerance was present, followed by lethargy, fainting episodes and hind legs ataxia. These findings were not permanent and most frequently occurred after a short burst of intense run. At that age, the referring doctor found liver and kidney dysfunctions and polycythaemia (tab. 1, tab. 2). Based on clinical pathology results, the referring doctor prescribed drugs to support the liver function ( $\operatorname{Liv} 52^{\circledR}$ and Hepatiale forte ${ }^{\circledR}$ ) and recommended a re-evaluation in one month. Slight kidneys' dysfunction and polycythaemia were related with dehydration. One month later, the owner did not observe any improvement in the clinical signs and blood workup also revealed liver dysfunction and polycythaemia (tab. 1 and tab. 2). At that moment, the referring doctor recommended a cardiac examination to a specialist (unfortunately, the owner postponed the cardiac exam for one year, during which period, the clinical condition worsened).

Clinical exam identified a dog with a good body score. It was viable without any sign of illness. The pulse was with normal characteristics; thoracic palpation did not reveal a precordial thrill and no murmur was identified on heart auscultation. Respiratory rate at rest was normal (15 rpm);

Tab. 1. Evaluation of blood parameters of the dog with reverse PDA at 10 and 11 months old

\begin{tabular}{cccccccccc}
\hline & ALAT & ASAT & BUN & Creat. & Chol. & TG & TP & Calcium & Mg \\
& $\mathbf{1 0 - 4 0}$ & $\mathbf{1 0 - 4 0}$ & $\mathbf{1 0 - 2 9}$ & $\mathbf{0 . 6 - 1 . 6}$ & $\mathbf{1 2 0 - 3 0 0}$ & $\mathbf{2 5 - 1 5 0}$ & $\mathbf{5 . 5 - 7 . 5}$ & $\mathbf{8 . 5 - 1 1 . 2}$ & $\mathbf{1 . 7 - 2 . 4}$ \\
\hline $\begin{array}{c}\mathbf{1 0} \\
\text { months }\end{array}$ & $143 \mathrm{U} / \mathrm{L}$ & \multirow{2}{*}{$56 \mathrm{U} / \mathrm{L}$} & \multirow{2}{*}{$48 \mathrm{mg} / \mathrm{dl}$} & $2.2 \mathrm{mg} / \mathrm{dl}$ & $\begin{array}{c}245 \\
\mathrm{mg} / \mathrm{dl}\end{array}$ & $\begin{array}{c}76 \\
\mathrm{mg} / \mathrm{dl}\end{array}$ & $\begin{array}{c}6.4 \\
\mathrm{~g} / \mathrm{l}\end{array}$ & $\begin{array}{c}12.3 \\
\mathrm{mg} / \mathrm{dl}\end{array}$ & $\begin{array}{c}2.2 \\
\mathrm{mg} / \mathrm{dl}\end{array}$ \\
\hline $\begin{array}{c}\mathbf{1 1} \\
\text { months }\end{array}$ & 132 & 43 & 35 & 2.0 & 213 & 72 & 6.7 & 11.9 & 2.1 \\
& $\mathrm{U} / \mathrm{L}$ & $\mathrm{U} / \mathrm{L}$ & $\mathrm{mg} / \mathrm{dl}$ & $\mathrm{mg} / \mathrm{dl}$ & $\mathrm{mg} / \mathrm{dl}$ & $\mathrm{mg} / \mathrm{dl}$ & $\mathrm{g} / \mathrm{l}$ & $\mathrm{mg} / \mathrm{dl}$ & $\mathrm{mg} / \mathrm{dl}$ \\
\hline
\end{tabular}


thoracic auscultation was normal as well. Oral mucous membranes had reddish appearance.

Clinical pathology revealed liver dysfunction, with polycythaemia (tab. 3, tab. 4).

ECG identified a sinus rhythm with deep $S$ wave in inferior leads, aspect consistent with right heart enlargement.

Two-D echocardiography identified a big right atrium and a concentric rightventricle hypertrophy (Fig. 1a). The left heart had a normal configuration, and left atrium to aorta ratio (LA:AO) was $<1.5$ (normal ratio). Colour Doppler exam of tricuspid and mitral valves did not reveal any regurgitation. Pulmonary artery diameter was larger than aortic root diameter (Fig. 1b) and flattening of intraventricular septum (IVS) was also present (Fig. 1c). These abnormalities are consistent for pulmonary hypertension. Acceleration time divided by ejection time (AT/ET) was less than $30 \mathrm{~ms}$, a finding also characteristic for pulmonary hypertension. Spectral Doppler examination of pulmonary artery and aorta revealed a normal velocity. At the level of pulmonary artery, we identified an orifice which had $6 \mathrm{~mm}$ diameter (Fig.1d), which represents the communication with aorta; flow direction was from the pulmonary artery to the aorta. Echographic examination raised the suspicion of extracardiac arteriovenous shunt, which was proven by performing "bubble study" and identification of "micro-bubbles" into the abdominal aorta.

In one study of patients diagnosed with PDA, Bichon frise breed was overrepresented (12.1\% of cases) (Sauders et al., 2014). Other breeds reported to present high risk to develop PDA are Chihuahua, Poodle, German shepherd, Pomeranian, Maltese and Yorkshire terrier (Saunders et al., 2014); the vast majority of patients with PDA are females and median weight is 3.6 kilo (Sauders et al., 2014). Right-to-left shunt (reverse PDA) is a rare condition and it accounts for less than 1\% of PDA cases (Ferasin et al., 2007). In normal PDA, the shunt direction is left-to-right, systemic pressure being at least fivefold higher than pulmonary pressure and if left untreated, the left heart dilates and finally fails. In reverse PDA, there are few situations in which there is a higher pulmonary pressure than systemic pressure. These happen when large left-to-right shunts are present initially, but flow will reverse due to progressively increasing pulmonary resistance (Ferrasin et al., 2007), or may be a consequence of persistence of foetal circulation (pulmonary hypertension). In our case, it is difficult to say

Tab. 2. Haematology at 10 and 11 months old

\begin{tabular}{|c|c|c|c|}
\hline & $\begin{array}{c}\text { Hematocrit } \\
\% \\
\end{array}$ & $\begin{array}{c}\text { Red blood cell count } \\
5.5-8.5 \times 10^{12} / L \\
\end{array}$ & $\begin{array}{c}\text { Hemoglobin } \\
12-18 \mathrm{~g} / \mathrm{L}\end{array}$ \\
\hline 10 months & 71 & $9.5 \times \times 10^{12} / L$ & 19 \\
\hline 11 months & 69 & $9.8 \mathrm{x} \times 10^{12} / L$ & 19 \\
\hline
\end{tabular}

Tab. 3. Evaluation of blood parameters when the dog was 2 years old

\begin{tabular}{cccccccccc}
\hline & ALAT & ASAT & BUN & Creat & Chol. & TG & TP & Calcium & Mg \\
& $\mathbf{1 0 - 4 0}$ & $\mathbf{1 0 - 4 0}$ & $\mathbf{1 0 - 2 9}$ & $\mathbf{0 . 6 - 1 . 6}$ & $\mathbf{1 2 0 - 3 0 0}$ & $\mathbf{2 5 - 1 5 0}$ & $\mathbf{5 . 5 - 7 . 5}$ & $\mathbf{8 . 5 - 1 1 . 2}$ & $\mathbf{1 . 7 - 2 . 4}$ \\
\hline $\mathbf{2}$ & 98 & 43 & 27 & 1.8 & 270 & 90 & 6.1 & 11.5 & 1.9 \\
years & $\mathrm{U} / \mathrm{L}$ & $\mathrm{U} / \mathrm{L}$ & $\mathrm{mg} / \mathrm{dl}$ & $\mathrm{mg} / \mathrm{dl}$ & $\mathrm{mg} / \mathrm{dl}$ & $\mathrm{mg} / \mathrm{dl}$ & $\mathrm{g} / \mathrm{l}$ & $\mathrm{mg} / \mathrm{dl}$ & $\mathrm{mg} / \mathrm{dl}$ \\
\hline
\end{tabular}

Tab. 4. Haematology of dog with reverse PDA at 2 year age

\begin{tabular}{|c|c|c|c|}
\hline & $\begin{array}{c}\text { Hematocrit } \\
\% \\
\end{array}$ & $\begin{array}{c}\text { Reb blood cell count } \\
5.5-8.5 \times 10^{12} / L \\
\end{array}$ & $\begin{array}{c}\text { Hemoglobin } \\
12-18 \mathrm{~g} / \mathrm{L}\end{array}$ \\
\hline 2 years & 75 & $10.5 \times \times 10^{12} / L$ & 21 \\
\hline
\end{tabular}


precisely if the cause of reverse PDA is a large shunt or primary hypertension, but none of the doctors that examined the dog before us mentioned about any murmur, and knowing that the left heart had a normal morphology, we would rather sustain that primary hypertension as being the cause of the reverse PDA. Pulmonary hypertension is backed by the following findings: flattening of IVS, paradoxical motions of interventricular septum and dilation of pulmonary artery. One important feature of reverse PDA is the lack of audible murmur which contrasts with left-to-right PDA, where there is a continuous murmur, blood being shunted from the aorta into the pulmonary artery in both systole and diastole. Intense murmur in left-to-right PDA reflects the high pressure difference between aorta and pulmonary artery. In right-to-left PDA, there is a flow reversal, the flow from pulmonary artery to aorta is minimal, this reflecting small pressure difference between the vessels.

Polycythaemia is an important feature in case of reverse PDA. The shunt opens in the aorta distal to vessels that supply the head and forelimbs.
Arteriovenous shunt will stimulate production of red blood cells by the bone marrow. Hind legs' lameness is also explained by low oxygen concentration in the caudal part of the body. Blood gas analyses from blood collected from a cephalic and caudal vessel confirmed this difference (Ferasin et al., 2007).

There are different treatment assessments between left-to-right PDA and right-to-left PDA. In left-to-right cases, shunt occlusion must happen as fast as possible and different techniques are available (classic intervention, coil or Amplatzer occluder) (Stauthmmer et al., 2015). In right-toleft shunt, ductal occlusion is contraindicated due to the risk of right sided heart failure and sudden death. In reverse PDA, one major therapeutic objective is to control polycythaemia, which can be carried out by phlebotomy, or through drugs administration (hydroxyurea or methotrexate). Pulmonary hypertension treatment is another important objective in reverse PDA treatment. The most efficient drug is Sildenafil (1-2 mg/ $\mathrm{Kg} / 2 \mathrm{xday}$ ). Depending on the clinical signs, other drugs must be added $\left(\right.$ Vetmedin $^{\circledR}{ }^{\circledR}$, ACEIs, and
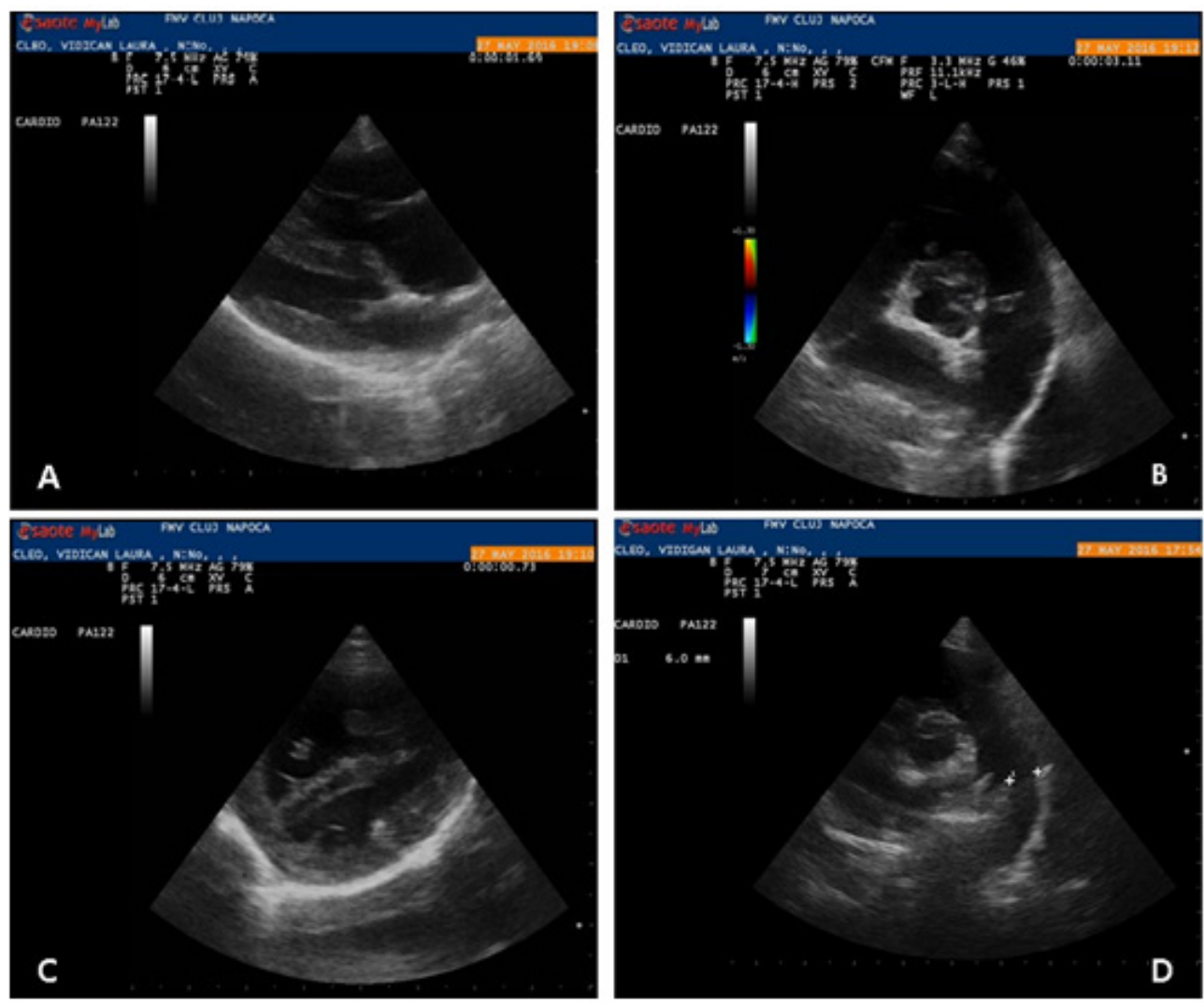

Fig. 1. (a). Right ventricle hypertrophy (b). Dilation of pulmonary artery (c). Flattening of interventricular septum (d). The opening of the shunt at pulmonary artery level 
Furosemide). In our case, we tried to keep the haematocrit level below $65 \%$, and we succeeded through phlebotomy (20 ml every three months), and the dog has been receiving Sildenafil (2 mg/ Kg bid). Two weeks after we started treatment, the owner observed an improvement in the clinical signs, which persisted for 6 months after reverse PDA was diagnosed.

\section{CONCLUSIONS}

Reverse PDA is a rarely diagnosed congenital heart disease. Polycythaemia in young dogs could raise the suspicion of reverse PDA. For positive diagnosis, echocardiography and bubble study are required. ECG is not a sensitive tool for diagnosis.

\section{REFERENCES}

1. Ferasin L, Rizzo F, Darke PGG (2007). Original investigation of right-to-left shunting patent ductus arteriosus in an Irish setter puppy. Veterinary Journal 173:443 - 448.
2. Gournay V (2011). The ductus arteriosus: Physiology, regulation, and functional and congenital anomalies. Arch of Cardiovascular Disease 104:578-585.

3. Israel N, French AT, McEwan JD, Welsh ME (2003). Patent ductus arteriosus in the older dog. Journal of Veterinary Cardiology 5(1):13-21.

4. Oliveira P, Domenech O, Silva J, Vannini S, Bussadori R (2011). Retrospective review of congenital heart disease in 976 dogs. J Vet Intern Med 25:477-483.

5. Saunders AB, Gordon SG, Boggess MM, Miller MW (2014). Long-term outcome in dogs with patent ductus arteriosus: 520 cases (1994-2009). J Vet Med 28:40-410.

6. Schrope DP (2015). Prevalence of congenital heart disease in 76.301 mixed breed dogs and 57.025 mixed-breed cats. J of Vet Cardio 17(3):192-202.

7. Seibert RL, Maisenbacher HW, Prosek R, Adin D, Arsenault WG, Estrada AH, (2012). Successful closure of left-to-right patent ductus arteriosus in three dogs with concurrent pulmonary hypertension. J of Vet Cardio 12:67 - 73.

8. Stauthmmer CD, Olson J, Leeder D, Hohnadel K, Hanson M, Tobias AH (2015). Patent ductus arteriosus occlusion in small dogs utilizing a low profile Amplatz canine duct occluder prototype. Journal of Veterinary Cardiology $17: 203-209$. 